\title{
LA FRONTERA HISPANO-PORTUGUESA EN EL RÍO MIÑO EN EL TRATADO DE LÍMITES DE 1864. DESLINDE Y ORDENACIÓN DE UN TERRITORIO FLUVIAL CONFLICTIVO ${ }^{1}$
}

\author{
Jacobo García Álvarez \\ Departamento de Humanidades: Historia, Geografía y Arte e Instituto de Historiografía \\ Julio Caro Baroja \\ Universidad Carlos III de Madrid \\ Paloma Puente Lozano \\ Instituto de Historiografía Julio Caro Baroja \\ Universidad Carlos III de Madrid
}

\section{RESUMEN}

Esta contribución ofrece una síntesis de algunos de los principales debates que tuvieron lugar durante el proceso de negociación del Tratado de Límites de Lisboa de 1864 y sus Anexos en relación con el deslinde y la regulación de los usos y aprovechamientos en el espacio fronterizo definido por el curso del río Miño. El trabajo se compone de tres partes principales. En la primera se examinan los principios y criterios recogidos en la tratadística y la práctica jurídica relativa a las fronteras fluviales en Europa y, de modo más concreto, la península ibérica, a mediados del siglo XIX. En la segunda se repasan, sucesivamente, los problemas existentes en la frontera del Miño a los que dicho Tratado intentó poner solución y las discusiones que se desarrollaron en el seno de las Comisiones Mixtas luso-españolas que, entre 1855 y 1862, trabajaron en el reconocimiento y delimitación de este tramo fronterizo. Finalmente, se aborda el análisis de los acuerdos y disposiciones establecidos en el Tratado y en su primer Anexo en relación con la frontera miñota, y que comprenden no sólo los criterios con los que ésta se deslindó y demarcó, sino también algunas medidas relevantes orientadas a la gestión y ordenación de este conflictivo espacio fluvial.

1. Trabajo realizado en el marco del Proyecto «La frontera hispano-portuguesa: delimitación territorial y representaciones geográficas (1800-1936). El caso de Galicia-Norte Portugal» (CSO2011-25776), financiado por el Ministerio de Economía y Competitividad. 
Palabras clave: frontera hispano-portuguesa, Comisiones de Límites, río Miño, Tratado de Lisboa de 1864, delimitación, gestión y ordenación del territorio.

\section{ABSTRACT}

The Spanish-Portuguese boundary along the Minho River as established by the 1864 Treaty of Limits: delimitation and planning of a controversial fluvial territory.

This contribution aims to offer an overview of key discussions held during the process of negotiation of 1864 Treaty of Lisbon and its Annexes, regarding demarcation and regulation of usages and exploitation within the bordering space defined by the Minho River. This paper is divided into three main sections. Firstly, legal tenets and criteria gathered in mid-nineteenth century treaties and legal practices relating to river boundaries in Europe, and particularly in Iberian Peninsula, are analyzed. Secondly, the paper reviews main problems existing within this section of the border, to which the Treaty of Limits sought to give solution. Special attention is paid here to discussions held within Spanish-Portuguese Joint Commissions, which carried out the reconnaissance and demarcation of this river boundary between 1855 and 1862. Thirdly, agreements and final settlements achieved by the 1864 Treaty and its first Annex relating to the Minho River boundary are analyzed in order to understand both the criteria followed to demarcate this boundary and the meaning of some relevant decisions made to manage and plan this controversial fluvial space.

Keywords: Spanish-Portuguese boundary, Boundary Commissions, Minho River, 1864 Treaty of Lisbon, territorial delimitation, management and planning.

\section{INTRODUCCIÓN}

El Tratado de Límites entre España y Portugal firmado en Lisboa el 29 de septiembre de 1864, que cumplió recientemente su 150 aniversario, estableció las bases para trazar de manera precisa y definitiva la línea fronteriza comprendida desde la desembocadura del río Miño hasta la unión del río Caya con el Guadiana. Su texto se compone de un preámbulo y treinta y un artículos, y fue completado en 1866 con dos Anexos de Reglamentos relativos, respectivamente, a los ríos limítrofes y los prendamientos de ganado (MAEC, 2005). Las operaciones para ejecutar la demarcación prevista en dicho Tratado se prolongaron durante cerca de cuarenta años, concluyendo con el Acta General de Demarcación, aprobada en Lisboa el 1 de diciembre de 1906. Un Convenio posterior firmado, también en la capital portuguesa, el 29 de junio de 1926 delimitó la frontera desde la confluencia del río Cuncos con el Guadiana hasta la desembocadura de éste en el mar, completando así el trazado continental de la Raya, con excepción del tramo correspondiente al municipio de Olivenza, que, objeto de un conocido contencioso diplomático, quedó fuera de los modernos Tratados de Límites luso-españoles (Teixeira de Sampaio, 2001; Cajal, 2003). 
Al igual que los Tratados de Bayona firmados entre 1856 y 1868 por los gobiernos de España y Francia, que delimitan de forma definitiva la frontera entre esos dos países (Capdevila, 2009), el Tratado de Lisboa de 1864 expresa la firme voluntad de los Estados liberales español y portugués por deslindar de forma precisa, exclusiva e indivisible los territorios bajo su soberanía. En este sentido, el Tratado trató de poner fin a numerosos contenciosos territoriales en áreas donde la línea fronteriza no estaba claramente delimitada; acabó con la anómala situación que presentaban determinados núcleos o términos partidos por dicha línea (caso de los denominados «pueblos promiscuos»); y supuso también la desaparición del llamado Coto Mixto, un enclave de estatus político y administrativo ambiguo, heredado del Antiguo Régimen, que gozaba de múltiples privilegios y escapaba en muchos aspectos a la soberanía de los dos reinos (García Mañá, 2000; Godinho, 2011; Cairo y Godinho, 2013). Las tareas principales de preparación y ejecución del Tratado se encomendaron a Comisiones Mixtas de Límites, creadas a partir de 1854 y protagonizadas, desde el punto de vista profesional, por diplomáticos y facultativos militares de ambos países. Para llevar a cabo su cometido, tales Comisiones recabaron y al mismo tiempo produjeron una ingente documentación, la mayor parte de la cual permanece inédita en diversos archivos de Lisboa y Madrid, y que incluye, de manera destacada, diferentes tipos de mapas, croquis y descripciones geográficas de la línea fronteriza y sus áreas próximas (Dias, 2009; García y Puente, 2015).

El presente trabajo se centra en la delimitación de uno de los sectores fronterizos que suscitó mayores controversias en el proceso de preparación del Tratado de Límites de 1864 como fue el definido por el río Miño. Sobre este tramo de la Raya existen ya estudios que han abordado determinadas contiendas anteriores al XIX (Herzog, 2015) y ofrecido una perspectiva panorámica de su origen y evolución (García Mañá, 1993), así como de los principales antecedentes, hitos y representaciones cartográficas del proceso de delimitación asociado al Tratado de Lisboa (García y Puente, 2015b). Teniendo en cuenta tales referencias, a las cuales nos remitimos, la presente contribución se detendrá de forma más específica y detallada en el análisis de las negociaciones y disposiciones del Tratado de 1864 relativas a este sector de la frontera, incluyendo las consignadas en el Anexo o Reglamento sobre ríos limítrofes complementario de dicho Tratado. La investigación aquí expuesta se apoya en el análisis de las fuentes disponibles, fundamentalmente, en el Archivo Histórico Nacional y, dentro de este conjunto, presta una atención especial a la documentación de carácter geográfico y cartográfico.

El texto se articulará en tres partes principales, aparte de la introducción, las conclusiones y la bibliografía. En primer lugar, se ofrece una breve síntesis del tratamiento que recibieron las fronteras fluviales en la tratadística decimonónica europea y, especialmente, ibérica. A pesar de presentar ésta una marcada 
diversidad, contenía una serie de principios, en su mayoría de origen romano, relativos a la regulación de la propiedad y la jurisdicción generados por los cambios en los ríos, que ordenaban y reflejaban a su vez la amplia casuística de la práctica legal de los tratados modernos respecto a las fronteras fluviales.

En segundo lugar, el trabajo aborda los debates sobre la delimitación del río Miño que tuvieron lugar entre 1854 y 1864, durante las negociaciones y trabajos preparatorios del Tratado de Lisboa. Para ello, se presentan brevemente las características geográficas de este espacio fluvial a mediados del siglo XIX, así como los principales conflictos que suscitaba y que el Tratado intentó regular, a saber: los problemas de navegación del río; los perjuicios derivados de las crecidas del mismo; la proliferación de ciertos usos ilegales o poco regulados, como el contrabando y la construcción de pesquerías y otro tipo de obras hidráulicas; y la disputa sobre el uso y soberanía de ciertas islas fluviales. A partir del análisis de tales antecedentes, la contribución se centra en analizar cuáles fueron los debates que se desarrollaron en el seno de las Comisiones Mixtas de Límites que trabajaron en el reconocimiento de este tramo de frontera y en el estudio de la documentación histórica, jurídica y geográfica movilizada o producida directamente por estas Comisiones en relación con la delimitación del mismo. Por último, el artículo analiza los acuerdos y disposiciones que finalmente se consignaron en el Tratado y en su primer Anexo en relación con la delimitación, gestión y ordenación de este sector fronterizo.

\section{EL TRATAMIENTO DE LAS FRONTERAS FLUVIALES EN LA DIPLOMACIA Y LA

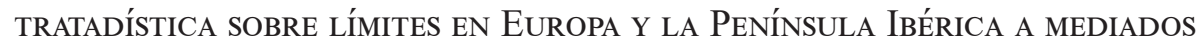 DEL SIGLO XIX}

La delimitación de fronteras apoyadas en cursos fluviales configuró un objeto de tratamiento sistemático y recurrente en los primeros tratados y ensayos generales del derecho internacional (hasta el siglo XIX denominado, mayoritariamente, derecho de gentes). Sin perjuicio de la extensa y antiquísima tradición normativa existente en relación con la propiedad y los límites jurisdiccionales de tipo fluvial (que en Europa se remonta al derecho romano y, en el contexto particular ibérico, incluye referentes de enorme relevancia, como los contenidos en las Siete Partidas) ${ }^{2}$, la codificación moderna de esta cuestión se debe, esencialmente, al tratamiento específico que recibe en las obras de Grocio (De

2. En especial, la Partida III, título 28, leyes 26 a 32, donde se abordan las cuestiones de adquisición de propiedad como consecuencia de las crecidas de los ríos, en función de cuáles sean las causas de éstas y de que puedan o no medirse dichos cambios; la manera de partir las islas que se forman en los ríos entre los propietarios de las riberas (dependiendo de cómo éstas se formen y a qué causa pueda atribuirse su formación); a quién y bajo qué régimen debe pertenecer la tierra seca que era antiguo cauce de un río y cómo cambia la propiedad de la tierra donde se forma el nuevo cauce, etc. Sobre la edición consultada, véase Alfonso X (1767: 372-375). Cfr. 
jure belli ac pacis, 1625), Vattel (Droit des Gens, 1758) o Gérard de Rayneval (Institutions du Droit de la nature et des gens, 1803) ${ }^{3}$. Éstas inspiraron en buena medida a algunos de los primeros tratados ibéricos modernos en la materia, como los de José Olmeda y León (Elementos del derecho público de la paz y la guerra, 1771), José María de Pando (Elementos del derecho internacional, 1843), o Antonio Riquelme (Elementos de derecho público internacional, 1849), así como los de Vicente Paiva (Elementos de direito das gentes, 1850) y Antonio Lobo (Noções geraes sobre o direito das gentes, 1853).

La importancia atribuida a estas cuestiones en el derecho internacional decimonónico se relaciona directamente con la relevancia política que este problema adquiere en la primera mitad de ese siglo. Por una parte, la preocupación por la fijación de fronteras lineales precisas fue algo intrínseco a la propia consolidación de las estructuras administrativas de los estados-nación europeos y a la sustitución de las instituciones y formas de gobierno del Antiguo Régimen. Por otra, la cuestión de las fronteras fluviales tomó cada vez más protagonismo debido al incremento de la navegación comercial en los ríos, así como con los enormes cambios del mapa político europeo y americano aparejados a ciertos procesos (como los derivados de la expansión de la Francia revolucionaria y napoleónica, o, en las colonias americanas, de la independencia de la mayoría de ellas). Los principios generales establecidos a partir del Congreso de Viena fueron aplicándose posteriormente en los tratados bilaterales de navegación correspondientes a los principales ríos (entre ellos los primeros en aprobarse en España, relativos al Tajo y el Duero $)^{4}$, si bien no se logró establecer un criterio único en materia de delimitación fluvial ${ }^{5}$.

Teclaff (1991: 61 y ss) y del Vas Mingo (1999) sobre la influencia de ciertas disposiciones de las Partidas en los territorios hispanoamericanos.

3. Las obras de Grocio, Vattel y Gérard de Rayneval se vertieron al castellano por vez primera, respectivamente, en 1925 (Del Derecho de la guerra y de la paz, traducción de J. Torrubiano Ripoll, Madrid, Ed. Reus), 1820 (Derecho de Gentes o Principios de la Ley Natural aplicados a la conducta y a los negocios de las naciones y los soberanos; traducida por M. Pascual Hernández, Madrid, Imprenta de la Compañía) y 1821 (Instituciones del Derecho natural y de gentes, traducida por M. Antonio López, Madrid, Imprenta de la Compañía). Las cuestiones relativas a los límites fluviales se tratan en: Grocio (1925, Libro II, cap. III, p. 324 y ss), Vattel (1758, Libro I, cap. XXII, p. 233 y ss), Gérard de Rayvenal (1821, Libro I, capítulo XXII y Libro II, capítulo 10) de las citadas ediciones españolas.

4. Nos referimos al Convenio para la libre navegación de los ríos Tajo y Duero de 30 de agosto de 1829; y al Tratado sobre la navegación del Duero de 31 de agosto de 1835, completado por un Reglamento de Ejecución de 23 de mayo de 1840 (MAEC, 2005, pp. 155-148). Sobre esta cuestión, véase Sereno (2011).

5. Por ejemplo, en 1792 el Consejo Ejecutivo francés dispuso que los obstáculos a la navegación eran contrarios a los principios del derecho natural. Las propias obras de Grocio y Vattel sustentaban el principio de libertad de navegación en los ríos internacionales. El artículo 109 del Acta Final del Congreso de Viena, firmada en junio de 1815, confirmó definitivamente el derecho a la libre navegación de los ríos internacionales en lo que respectaba al comercio, aunque lo 
En el caso ibérico, este corpus iusinternacionalista presentaba un marcado rasgo de diversidad debido, entre otras cosas, a la propia antigüedad de los conflictos territoriales vinculados a los cursos fluviales fronterizos entre España y Portugal, tanto en la América colonial como en la península ibérica, pues dichos problemas habían aparecido mucho antes del establecimiento de los modernos Tratados de Límites que solventaban dichas cuestiones, y recibido, por tanto, una variedad de argumentaciones jurídicas y soluciones diplomáticas ${ }^{6}$.

La casuística en ese sentido era diversa, e incluía, entre otras, discusiones sobre si el cambio del curso de los ríos afectaba también a la frontera y, por tanto, a la soberanía de los monarcas respectivos acerca de dichos territorios; sobre la pertenencia de los terrenos de aluvión formados por las deposiciones de los ríos en las márgenes de los mismos; o sobre el dominio y reparto de las islas situadas en los cursos fluviales ${ }^{7}$. Por ejemplo, Riquelme (1849: 84) distinguía claramente entre los cambios del curso del río producidos de forma natural y los que pudieran producirse por causas humanas, algo que fue central en la discusión sobre la frontera miñota, como veremos más adelante. Para los primeros diferenciaba entre los cambios totales (como, por ejemplo, los que supusieran el abandono entero del álveo o cauce original), que debían resolverse conservando la línea fronteriza allí donde ésta estaba antes del cambio (esto es, en el lecho original, aunque éste hubiera quedado seco); y los progresivos, en los que el derecho internacional convenía mudar el límite fronterizo siguiendo el nuevo curso del río. Respecto a las alteraciones artificiales o causadas por la

dejaba supeditado a los reglamentos de policía de dicha navegación, por lo que en la práctica esta norma se vio muy limitada. Cfr. Telcaff (1991: 47 y 49 y ss.) y Kaeckenbeeck (1959: 16-24). Posteriormente, el Congreso de Berlín de 1855 enfatizó este principio de la libertad de navegación, y el Tratado de Versalles de 1919 llegó al extremo de conceder prioridad a la navegación por encima de todos los demás usos.

6. Además del ya referido Tratado de 1864 entre España y Portugal, los Tratados de Madrid (1750) y San Ildefonso (1777), que estipulaban cómo había de fijarse la frontera entre España y Portugal en la América colonial, señalaron los cursos fluviales y otros accidentes naturales como los más convenientes para «servir de límite fijo e indeleble» (art. VI). Para un pormenorizado análisis de los antecedentes medievales y modernos de algunos de estos conflictos territoriales y los modos de resolverlos véase Herzog (2015), así como Zusman (2000) para el caso de la organización territorial en torno a las fronteras coloniales.

7. Los manuales de de Olmeda y de Pando ya mencionados recogían, en lo sustancial, el cuerpo doctrinal relativo a los principios de avulsión (avulsio) y aluvión (alluvio e ius alluvionis) propios del derecho romano, así como otros relativos a los cambios en los ríos fronterizos, como «mutatio allvei», "circumluvio», etc., incorporados al Ius Gentium por Grocio y Vattel y por los romanistas modernos. Como hemos mencionado, muchas de esas cuestiones ya estaban recogidas en Las Siete Partidas.

Las cuestiones relativas a los límites fluviales se tratan en: de Olmeda (1771, tomo 1: 198 y ss), de Pando (1843: 107 y ss y 266 y ss.) y Riquelme (1848, vol. 1: 82 y ss.). Para un análisis de la clara y fuerte influencia de Vattel y otros autores modernos en los publicistas españoles, especialmente en el trabajo de José de Olmeda y León, véase Morales (1998) y de la Rasilla del Moral (2013). 
mano del hombre, el derecho internacional era unánime en subrayar el carácter ilícito de la construcción de «obras hidráulicas que puedan contribuir a cambiar su curso, o a impedir[lo] $\rangle^{8}$, puesto que esto se entendía como una usurpación de los derechos comunes de navegación. Asimismo, en lo tocante a la delimitación de las islas fluviales el tratado de Pando (1843: 107) se hacía eco de la doctrina prevaleciente a nivel internacional, que aconsejaba deslindar dichas islas en los ríos que los Estados poseyeran comúnmente:

el territorio de una nación incluye las islas por sus aguas circundadas. Si una ó más islas se hallan en medio de un rio ó lago que dos Estados posean por mitad, la línea divisora de las aguas deslindará las islas ó partes de ellas que á cada Estado pertenezcan, á menos que haya pactos ó una larga posesión en contrario (de Pando, 1843, 107).

Por último, en lo que respecta al criterio con que trazar las líneas limítrofes entre dos Estados que compartían un curso fluvial, en el momento en que se gesta la Comisión Mixta encargada de preparar el Tratado de 1864, el derecho internacional en materia de delimitación de ríos internacionales, si bien aceptaba ciertas reglas comunes, distaba de ser unánime en algunos aspectos ${ }^{9}$. Los Tratados de Límites firmados en el XVIII y la primera mitad del XIX, tanto dentro como fuera de España, ofrecen ejemplos diversos en este punto, pues aunque algunos fijaban la línea de frontera en la ribera de los estados limítrofes, dejando el río como condominio o tierra de nadie, otros la fijaban en la ribera de uno de los dos estados, dejando todo el curso fluvial en manos de uno, y otros, en fin, la establecían en el curso mismo del río (es decir, en su cauce o «álveo») $)^{10}$. En este caso, existían, a su vez, dos soluciones posibles sobre cómo y dónde fijar la línea fronteriza: bien en la línea media o mediana entre ambas orillas, siendo ésta la línea geométrica media del río, equidistante entre ambas orillas; bien en el thalweg, concepto que, como el citado Pando recogía, se utilizaba con diversos significados, no siempre equivalentes («el medio del canal principal», «los parajes más profundos del río») dependiendo del Tratado en cuestión. En opinión de algunos autores (en especial Caflisch, 1989), a comienzos del siglo XIX el criterio de la línea media o mediana era el más utilizado, tanto en ríos navegables como no navegables, pero a mediados del xIX dicho criterio, sin ser

8. Riquelme (1848: 84)

9. Un tratamiento más sistemático de la cuestión de las fronteras fluviales en el derecho internacional podemos encontrarlo en Kaeckenbeeck (1918), Bouchez (1963), Gómez de la Torre (2005), Caflisch (1989), Teclaff (1991) y Prescott y Triggs (2008: 215-232).

10. «Álveo», según el Diccionario de la lengua castellana, es «la madre del río o arroyo», o lo que es lo mismo, su cauce. El término «madre del río» es el que aparece precisamente en la traducción castellana que en 1820 hizo M. Pascual Hernández de la obra de Vattel, y es el término común en los manuales españoles de la época. 
abandonado, empezó a ser sustituido progresivamente, en los ríos navegables, por el del thalweg.

LOS DEBATES SOBRE LA DELIMITACIÓN DEL RÍO MiÑO DURANTE LA PREPARACIÓN DEL TRATADO DE LisboA

\section{Antecedentes}

Tal y como hemos expuesto con más amplitud en otros trabajos (García y Puente, 2015b), la frontera hispano-portuguesa definida por el curso del río Miño, de aproximadamente $75,5 \mathrm{~km}$ de longitud, tiene su origen a fines del siglo XI con la creación del Condado Portucalense, cuyo límite norte coincidía con dicho río. A pesar de su considerable antigüedad, no ha sido en absoluto una frontera pacífica (Barros, 1994), y algunas de las guerras y hostilidades que en diferentes momentos se han sucedido en torno a ella provocaron modificaciones territoriales transitorias (García Mañá, 1993). La estabilidad definitiva de este sector fronterizo no se alcanza verdaderamente hasta mediados del siglo xIX, cuando comienza una fase de notable mejoría en las relaciones entre los gobiernos de España y Portugal, en el marco de la cual tuvo lugar precisamente el inicio de las negociaciones que conducirían al Tratado de Límites de 1864.

Los principales problemas a los que dicho Tratado hubo de hacer frente fueron de varios tipos, en todo caso relacionados entre sí: las dificultades para navegar el río; los perjuicios derivados de las crecidas de éste sobre las riberas (que dificultaban ciertas prácticas agrícolas, destruían o modificaban significativamente sus márgenes y ponían en riesgo algunos núcleos de población); la importancia de ciertos usos ilegales o deficientemente ordenados, en especial el creciente contrabando y la construcción incontrolada de pesquerías, malecones y otras obras públicas; y las disputas sobre el uso y soberanía de determinadas islas fluviales creadas tanto por la dinámica natural del río, como, sobre todo, por los factores artificiales que acaban de mencionarse.

En efecto, en su condición de vía fundamental para las relaciones comerciales y transporte de mercancías entre las poblaciones de su ribera, y debido a su profundidad y elevado caudal, a fines del Antiguo Régimen el río Miño estaba punteado por una amplia hilera de barcas que permitían el pasaje, de un lado a otro, de personas, mercancías y animales, todas ellas sujetas al pago de diferentes impuestos (Iglesias, 1984). Pero junto a las barcas que operaban legalmente y bajo el control de las aduanas y contrarregistros instalados en la raya, existía también un importante tráfico con barcas que actuaban ilegalmente ejerciendo el contrabando (de diversos productos, en especial sal, trigo, paños y tabaco), un fenómeno típico de la frontera y documentado desde épocas muy antiguas (Freire et al., 2009) 
Además, al menos desde el siglo xvIII, el Miño presentaba diversos problemas de navegabilidad relacionados sobre todo con la presencia de numerosas islas y bancos de arena más o menos permanentes, de lo cual dieron testimonio los informes de los ingenieros militares destacados en la zona, entre los cuales cabe señalar, por su detalle, el derivado del reconocimiento practicado conjuntamente por el portugués Francisco Pegado y el español Celedonio Uribe, en 1852, pocos años antes de la formación de la Comisión Mixta de Límites ${ }^{11}$. Dicho informe ofrece datos abundantes acerca de la navegabilidad del Miño, la naturaleza de los terrenos en sus orillas, la anchura del cauce en sus distintos tramos, las variaciones del régimen y los factores que lo determinan, tanto naturales como artificiales. El informe da cuenta de que, en ese momento, el río sólo era navegable en el tramo comprendido desde la desembocadura hasta las proximidades de la localidad portuguesa de Seixeira, cerca de Monçao, aunque en el pasado lo hubiera sido hasta la ciudad de Ourense; ofrece una estimación de la inclinación general del río y de la velocidad media de la corriente para demostrar la navegabilidad en algunos de sus tramos; e insiste en que, de ser removidos los obstáculos que dificultan la navegación debido a causas artificiales, el río podría recuperar dicho uso. Se apunta a la pesca del salmón, la lamprea y otras especies fluviales como la causa principal de esta obstaculización del río, ya que la proliferación de pesquerías (también llamadas «pesqueras», pesqueiros o pesqueiras) en ambas orillas, construidas con estacas de madera o gruesas paredes de piedra dispuestas perpendicularmente a la dirección del río ${ }^{12}$, no sólo había generado la división del álveo del mismo en canales laterales, sino que además había provocado importantes cambios en el curso de las aguas. Entre ellos figuraban numerosos remolinos, pozos, saltos y rápidos, además de inflexiones de la corriente que provocaban desbordamientos sobre las márgenes opuestas y el anegamiento de zonas cultivables, así como seixos y rañas (montículos formados sobre todo la acumulación de cantos y guijarros, que daban lugar a pequeños saltos y cambios en la velocidad de la corriente), todo tipo de «secos» o arenales, e incluso verdaderas islas producidas por el desgajamiento de terrenos debido al nuevo cauce.

11. «Reconhecemento cavalheiro dos obstaculos que se oppoen a navegaão do rio Minho. Desde a foz na barra de Caminha até á confluencia do rio Trancoso...», realizado en agosto de 1852, pero revisado, firmado y enviado a las autoridades en 1860. Reproducido en Barreiros (19611965, vol. 3, fasc.I-II, doc. 99). Desde inicios de esa década de 1850 se insiste, sobre todo a iniciativa de los comerciantes y hacendados de Oporto y otras localidades fronterizas de la zona del Miño, en la necesidad de verificar y llevar a cabo nuevos estudios sobre la navegabilidad del río, a fin de que se realicen los trabajos necesarios para conseguir que éste sea navegable por ·buques de vapor». La documentación relativa a esta cuestión puede consultarse en el AGA, Caja 6566, legajo 109, expedientes 1 y 2.

12. Dichas construcciones estaban destinadas a la pesca del salmón, la lamprea y otras especies abundantes en este río (cfr. Alonso Rodríguez, 1989; Río y Rodríguez, 1992). 
La propiedad, la jurisdicción y los derechos de aprovechamiento de la mayoría de estas islas formadas en el río, que se usaban ocasionalmente para la producción de juncos y paja y para pasto de ganados, e incluso para pequeños cultivos, estaban claros a fines del Antiguo Régimen y no se discutieron en el proceso de delimitación de la frontera llevado a cabo en el siglo XIX. Pero en otros casos la jurisdicción y el aprovechamiento de estas islas suscitaban, desde los años finales del XVII, controversias intensas y recurrentes entre los habitantes de ambas márgenes, las cuales no se resolverían de hecho hasta el Tratado de 1864 , como veremos en los siguientes apartados..$^{13}$

\section{Las discusiones de la primera Comisión técnica (1855-1857)}

En octubre de 1854 los gobiernos de España y Portugal pusieron en marcha la creación de una Comisión Mixta encargada de proceder al arreglo de las cuestiones de límites pendientes entre ambos países desde la desembocadura del Miño hasta la confluencia de los ríos Caya y Guadiana (García y Puente, 2015a). Esta Comisión, formada por diplomáticos y militares, recibió la misión de verificar y reconocer sobre el terreno (comenzando por la desembocadura y el curso bajo del Miño) la referida línea fronteriza, así como la de proponer acuerdos provisionales sobre el modo de resolver los principales conflictos, de ahí que su naturaleza pueda considerarse fundamentalmente técnica. Las vicisitudes que experimentó este organismo permiten diferenciar, además, entre una primera Comisión técnica ${ }^{14}$, cuyas reuniones tienen lugar entre septiembre de 1855 y julio de 1857; y una segunda Comisión técnica, reunida entre octubre de 1858 y abril de 1862 , aunque de hecho su actividad comienza con anterioridad y prosigue hasta fines de 1863, cuando entran en funcionamiento las Comisiones propiamente diplomáticas que culminarían las negociaciones del Tratado.

La metodología de funcionamiento de la Comisión Mixta de Límites quedó establecida en un documento de instrucciones que fue negociado por ambos gobiernos desde octubre de 1854 hasta agosto de $1855^{15}$, y en el que quedó de

13. Herzog (2015: 192-2010) ofrece un análisis pormenorizado del conflicto suscitado en torno a las islas de Verdoejo a fines del siglo XVII y principios del XVIII.

14. Compusieron esta Comisión, por parte de España, los diplomáticos Fidencio Bourman Monsegur (presidente) y Evaristo Pérez de Castro (secretario), así como el ingeniero militar Ramón Madina y Orbeta; y por la de Portugal, los militares Frederico Leão Cabreira (presidente) y Guilherme Antonio da Silva Couvreur (secretario).

15. «Instrucciones para la Comisión Mixta encargada de la demarcación de la frontera entre los Reynos de España y Portugal, reformadas con arreglo a la correspondencia seguida al efecto entre los dos gobiernos», de 15 de octubre de 1855 (dicho documento, así como todos los demás relativos al proceso de negociación de las instrucciones generales, pueden consultarse en AHN, Sección M. ${ }^{\circ}$ de Exteriores, Tratados, Tr. 138, Neg. 207, Exp. 20). El texto referido está reproducido, en su versión portuguesa, en Barreiros (1961-1965, vol. 1, fasc. I-II, doc. 10) y en Teixeira de Sampaio (2001: 231-242). 
manifiesto que la principal finalidad de la Comisión era la de «sancionar» $\mathrm{y}$ «precisar» los límites de la frontera previamente existentes allí donde no hubiera dudas ni conflictos (procediendo, por tanto, a la demarcación de la misma), y, donde sí los hubiera, aclarar su trazado y dejarlo de una vez por todas señalado con precisión. Asimismo, en el párrafo 1 de dichas instrucciones, en su versión española, se estipulaba que en los tramos en que la frontera entre los dos países coincidiera con ríos los comisionados debía utilizar preferentemente el «álveo» de los mismos (la versión portuguesa utilizaba, sin embargo, la expresión thalweg) para fijar la divisoria internacional, salvo en aquellas corrientes en que éste tuviera tendencia a variar ${ }^{16}$, lo que, como veremos, se pudo comprobar en el caso del Miño en cuanto los comisionados comenzaron su reconocimiento.

Por tanto, puede afirmarse que la existencia secular de la frontera en el río Miño no se cuestionó en sí misma ${ }^{17}$. Enseguida se comprendió, no obstante, su carácter problemático y la relevancia de las controversias que afectaban a dicho tramo fronterizo, y, por tanto, la necesidad de regular los usos comunes y ordenar este espacio fluvial. Al igual que sobre cualquiera de las otras contiendas territoriales que existían a lo largo de la frontera, las instrucciones dadas los comisionados precisaban, además, que para efectuar el deslinde debían consultar los datos y documentos a disposición de las autoridades locales, y que en aquellos casos que hubiese de proceder a la repartición de los terrenos de uso común ello se haría de acuerdo a los derechos y los títulos de propiedad que se alegaran en cada caso.

Como ya se ha indicado, el proceso de deslinde de la frontera hispanoportuguesa comenzó por la desembocadura del río Miño, habiendo tenido lugar la constitución formal de la Comisión Mixta en Vigo el 9 de septiembre de

16. La versión española de las «Instrucciones» reza exactamente que los comisionados debían «rectificar ésta [la frontera] por el curso de los ríos que la han servido hasta aquí de límites, lo cual se fijará atendiendo al álveo de los mismos cuando no se note en ellos tendencia a variar» (AHN, Sección M. ${ }^{\circ}$ de Exteriores, Tratados, Tr. 138, Neg. 207, Exp. 20; para la versión portuguesa, véase Barreiros, 1961-1965, vol 1, fasc. I-II, doc. 10). El término álveo se utiliza en este contexto con el sentido de cauce o madre del río. La documentación generada por las Comisiones Mixtas en relación con el proceso de delimitación de la frontera miñota refleja una persistente confusión de los términos «álveo» y thalweg, siendo éste último utilizado desde el principio por los portugueses, y puntualmente por los españoles. Sobre los diversos significados atribuidos al término thalweg en el derecho internacional de fronteras, véanse Union Académique Internationale (1960: 601-603) y Caflish (1989).

17. En varios escritos pertenecientes a la documentación generada durante el proceso de negociación de las instrucciones para la Comisión durante 1854-55 se insiste, sobre todo por parte del lado español, en esta idea de que «no se trata ahora de establecer o crear, por decirlo así, la frontera, sino de fijar clara y terminantemente su línea; por manera que el cometido de la comisión mixta se reduce a declarar los límites donde estén claros y a fijarlos donde haya dudas, oscuridad o pretensiones contradictorios», según las propias palabras del Ministro plenipotenciario español en Lisboa, en documento fechado en Lisboa a 28 de junio de 1855 (AHN, Sección M. ${ }^{\circ}$ de Exteriores, Tratados, Tr. 138, Neg. 207, Exp. 20, doc. n. ${ }^{\text {o } 123) . ~}$ 
1855. Aunque diversos avatares políticos que afectaron a los comisionados portugueses retrasaron hasta junio de 1856 el reconocimiento conjunto del tramo fronterizo definido por el Miño, la delegación española trabajó por su cuenta en el asunto durante las semanas siguientes a la citada reunión, reconociendo el terreno y preparando cuidadosamente los argumentos que fijarían las directrices de su posición a lo largo del proceso negociador previo al Tratado de 1864. De esta etapa inicial, que tiene lugar esencialmente en septiembre y octubre de 1855 , datan algunos informes importantes de los comisionados españoles ${ }^{18}$ y las instrucciones enviadas a los mismos por el gobierno español en relación con este asunto ${ }^{19}$, así como un plano, obra del comisionado Ramón Madina y Orbeta, que se convirtió en un instrumento auxiliar clave no sólo para visualizar los principales problemas que dicho tramo fronterizo presentaba, sino también para tratar de probar algunos de los argumentos defendidos por la delegación española ${ }^{20}$.

La cuestión de la pertenencia de ciertas islas situadas en el curso del río Miño fue la que centró, sobre todo, los esfuerzos de estos primeros trabajos de la sección española de la Comisión Mixta. Básicamente, los principales conflictos territoriales afectaban, por un lado, a la isla Canosa (situada cerca de la desembocadura del río, frente a Caminha), sobre la cual parecía existir un acuerdo antiguo sobre su uso compartido entre españoles y portugueses; y, por otro lado, al islote Filla Boa y al grupo de las islas de Verdoejo (situadas en el tramo entre Tui/Valença y Salvaterra de Miño/Monçao). Dentro este grupo, las controversias afectaban especialmente a las islas de Cancela (o Caldelas), Ínsula Grande (o Isla Grande), Canguedo y Raña Gallega. Las dos primeras eran en aquel entonces de uso común, mientras que las segundas (que según algunos autores formaban de hecho una sola isla) parecían estar en posesión de los portugueses.

18. Nos referimos, especialmente, al informe, fechado en 5 de octubre de 1855 , que F. Bourman, presidente de la sección española de la Comisión de Límites, envía al gobierno dando noticia acerca de la cuestión de las islas del Miño. Bourman, acompañado por el secretario de la Comisión (E. Pérez de Castro) y el oficial facultativo de la misma (el capitán de ingenieros R. Madina y Orbeta), había realizado el reconocimiento de estas islas en el mes de septiembre de 1855 para comprobar si era cierto, como parecía, que algunas de ellas estaban siendo ilegítimamente poseídas por Portugal (AHN, Sección M. ${ }^{\circ}$ de Exteriores, Tratados, Tr. 138, Neg. 207, Exp. 20, despacho n. ${ }^{\circ}$ 7).

19. Instrucciones dadas a F. Bourman, con fecha de 17 de octubre de 1855, en respuesta al informe antes mencionado, indicando cómo había de procederse para el esclarecimiento de los derechos de propiedad de dichas islas (AHN, Sección M. ${ }^{\circ}$ de Exteriores, Tratados, Tr. 138, Neg. 207, Exp. 20).

20. «Plano de un trozo del río Miño desde la plaza de Tuy a Caldelas...», por el capitán de ingenieros Ramón Madina y Orbeta, fechado en Ourense el 1 de octubre de 1855 (AHN, Sección M. ${ }^{\circ}$ de Exteriores, Mapas y Planos, 114). Dicho plano fue acompañado de una extensa memoria, obra también de Madina y Orbeta, que constituye el anexo n. ${ }^{\circ} 4$ del referido despacho ${ }^{\circ}{ }^{\circ} 7 \mathrm{de}$ Bourman enviado al gobierno el 5 de octubre de 1855. 
Los informes que en octubre de 1855 remite al gobierno Fidencio Bourman, presidente de la sección española de la Comisión, denuncian la situación que en ese momento se daba respecto a estas islas del grupo de Verdoejo, reivindicándose su origen español con el argumento de haber sido originalmente parte de la ribera derecha (o gallega) del río, de la cual se habrían desprendido y alejado progresivamente por efectos de una corriente artificialmente alterada. Se critica que la isla Cancela, a pesar de no ser apta para el cultivo y seguir considerándose como «perteneciente por partes iguales a España y a Portugal», según palabras del propio Bourman, es usada y poseída de facto, sin embargo, por éste último país, acusándose a los portugueses de valerse de la proximidad de la misma a la orilla española para practicar impunemente el contrabando y «tener un pie» en territorio español. Asimismo, respecto de la denominada Raña Gallega, denunciaba Bourman que se la hubieran apropiado los portugueses cuando se tenía constancia de que en el pasado había pertenecido a la feligresía española de Caldelas y, posteriormente, por mitad a ambos países. Achacaba Bourman a la influencia de las pesquerías sobre la corriente y la dirección del río la aproximación progresiva del islote a la orilla portuguesa (de hecho, se hace referencia a la existencia original de dos islotes, cada uno perteneciendo a uno de los países, que se habrían unido generando el islote actual como consecuencia de la obstrucción del canal que los dividía, y que tras seguir perteneciendo en sus mitades a cada país, a mediados de la década de 1820 pasó a manos portuguesas).

Con respecto a la Ínsula Grande, situada muy cerca de la orilla derecha del Miño, el informe complementario del capitán de ingenieros Madina y Orbeta ${ }^{21}$, sostenía que el dominio de facto de los portugueses sobre la misma les dotaba de control de las aguas y la corriente en ese tramo del río, algo no sólo perjudicial para los intereses españoles, sino también peligroso desde el punto de vista militar: «es tal-advertía Madina- que si conviniese a sus miras e intereses futuros construir una plaza de guerra o cualquier fortaleza, [los portugueses] tendrían la ventaja inmensa de colocarse a caballo sobre el río, como se observa en algunas plazas de la Alemania que se hallan sobre el Rhin». Del reconocimiento del terreno y de su análisis topográfico y representación cartográfica (materializados en un plano adjunto a su informe), así como de «las declaraciones de muchos vecinos» (incluyendo los alcaldes pedáneos de Santiago de Baldranes y de Caldelas), el comisionado español concluía que en los últimos años el río había cambiado significativamente su cauce empujado por las pesquerías y malecones construidos en la orilla izquierda por los portugueses, anegando y desmembrado parte del territorio español. Y que, por tanto, el cauce natural y

21. Transcrito por el propio Bourman y adjunto como anexo n..$^{\circ} 4$ a su despacho n. ${ }^{\circ} 7$ de octubre de 1855, tal y como hemos indicado (AHN, Sección M. ${ }^{\circ}$ de Exteriores, Tratados, Tr. 138, Neg. 207, Exp. 20, despacho n. ${ }^{\circ}$ 7). 
antiguo (al que Madina llamaba el «verdadero cauce») era el que transcurría entre dicha isla y la orilla portuguesa y allí debía situarse el límite entre ambos países, de manera que esta isla había de ser «devuelta» por los portugueses a España. Más aún, el ingeniero explicaba la mayor abundancia de pesquerías en la margen izquierda del río porque para «los grandes lucros que sacan del contrabando, particularmente de sal, los portugueses necesitan dejar isletas en el medio del río y formar recodos en todas partes con el objeto de sustraerse a la vigilancia del cuerpo de Carabineros».

A la vista de los informes de Bourman y Madina, el gobierno español, en las instrucciones dadas al primero acerca de cómo tratar con los comisionados portugueses la cuestión del establecimiento de los derechos de propiedad de las mencionadas islas, recomendaba reivindicar la adjudicación a España de la Cancela y la Ínsula Grande por estar clara su mayor proximidad a la orilla española. Esta proximidad, insistían tales instrucciones, debía ser el principal argumento para reclamarlas, por encima incluso del método documental del esclarecimiento de los títulos de dichas islas con el fin de conocer si están o no bajo dominio de España. Puesto que la frontera que separa las jurisdicciones de ambos estados debe transcurrir por el «centro de las aguas», y este cauce principal es el que se ubica entre las mencionadas islas y la orilla portuguesa, éstas -concluía el documento- quedarían bajo dominio español y como parte, por tanto, de su territorio.

Con posterioridad a estos primeros trabajos de la sección española, en junio de 1856 se llevó a cabo la inspección conjunta con los comisionados portugueses del tramo fronterizo del Miño, que se hizo principalmente a bordo del barco de vapor que cubría por entonces la línea Caminha-Valença ${ }^{22}$. Tras verificar los comisionados con los testigos y autoridades locales la existencia de un acuerdo antiguo del uso común, para extracción de hierbas, de la isla Canosa y del compromiso de que no se cultivara allí para evitar las pretensiones de propiedad por parte de unos u otros, la Comisión acordó que, aún manteniéndose ese uso común, dicha isla pasara directamente a dominio de España, basándose principalmente en razones de proximidad a esa orilla.

Sin embargo, en octubre de 1856 el secretario de la delegación portuguesa de la Comisión, el ingeniero militar Gillherme Couvreur, en desacuerdo con el presidente de dicha delegación, Frederico Cabreira, remite a su gobierno un

22. Los resultados de dicho reconocimiento se recogen en los acuerdos consignados en el Acta de la sesión novena de la Comisión de Límites (Barreiros, 1961-65: vol I, fasc. I-II, doc.12; también el doc. 17). El Acta de la sesión octava de la Comisión, de junio de 1856, recogía ya la propuesta de la sección española de que las dos secciones de la Comisión repitiesen los reconocimientos que la sección española ya había practicado en septiembre de 1855 en aquella parte de la frontera, de manera que pudiese llegarse a un acuerdo sobre el deslinde en toda esta parte del Miño. 
extenso informe donde expresa una postura contraria a los acuerdos alcanzados en junio de 1856 y conculca los argumentos de los españoles y sus pretensiones sobre las islas de Verdoejo ${ }^{23}$. En dicho documento Couvreur desplegaba un minucioso análisis en el que combinaba argumentos basados en «algumas das regras da Fisica e Mechanica aplicada as vias fluviaes» (en otros pasajes alude a las «regras da ciencia aplicada») con otros apoyados en el estudio de la litología y morfología de las márgenes y de las islas en disputa, en testimonios locales (indicativos de ciertas «tradiciones») y en documentos legales antiguos. En su informe, el ingeniero portugués pretendía demostrar, por una parte, que el origen y proceso de formación de dichas islas eran distintos a lo expresado por los comisionados españoles, $y$, por otra, que el lugar exacto por el que verdaderamente iba la corriente del río en algunos puntos no era tampoco el señalado por los españoles. Según él, las islas de Verdoejo no procedían de fragmentos desprendidos de la ribera española del río, sino que habían surgido de terrenos naturales de aluvión que formaban originalmente una sola isla flanqueada, a izquierda y derecha, por sendos canales navegables, el más importante de los cuales era el derecho, hasta que las pesquerías construidas en la orilla española provocaron su obstrucción, anexaron prácticamente la Ínsula Grande a dicha orilla y forzaron a los portugueses a protegerse (construyendo sus propias pesquerías) del empuje causado por el desvío de la corriente hacia el margen izquierdo. Couvreur hacía referencia, asimismo, a diversos documentos históricos y jurídicos que venían a apoyar la posición portuguesa respecto de las mencionadas islas y recurría a la autoridad del Tratado de Utrecht entre España y Portugal (1715), cuyo artículo 7 alude a una sola isla de Verdoejo, ocupada entonces por los españoles y que debía ser devuelta a los portugueses ${ }^{24}$. Y, en consecuencia, recomendaba al gobierno portugués que mantuviese la pretensión sobre el uso común de la isla Canosa y que no se cediera respecto a las de Verdoejo, que debían considerarse una sola isla en origen sobre la que los portugueses poseían título desde antiguo. Asimismo, Couvreur aconsejaba proceder al dragado del río para mejorar su navegabilidad en ese tramo de Caminha a Valença (incluyendo la destrucción de la isla Cancela, de terreno improductivo); eliminar algunas pesquerías que también lo obstaculizaban; y, finalmente, desobstruir algunos de los canales,

23. Dicho informe se halla reproducido en Barreiros (1961-1965: vol. I, fasc. III-IV, docs. 28 y 29). Un informe posterior del mismo autor (recogido también en Barreiros, 1961-1965: vol. I, fasc. III-IV, doc. 30) es remitido al gobierno portugués en abril de 1857, ratificando las opiniones y argumentos dados ya en el primero.

24. Como ha documentado Herzog (2015: 192 y ss.), el gobierno español matizaría posteriormente este acuerdo estimando que la inclusión de la isla en el Tratado pudo deberse a un error, pues, según la documentación recogida, no podía probarse que la isla fuera realmente portuguesa antes de la guerra que motivó el Tratado y por tanto no podía considerarse susceptible de restitución. 
próximos a la orilla española, de cuya obstrucción habían resultado el desvío del primitivo cauce principal y la bifurcación de la isla de Canguedo.

\section{Las aportaciones de la segunda Comisión técnica (1858-1862)}

La decisión del gobierno portugués de no ratificar las resoluciones adoptadas provisionalmente por la primera Comisión técnica hasta después de revisar minuciosamente sus trabajos supuso retomar, entre otras cuestiones, las relacionadas con el deslinde de la línea fronteriza definida por Miño. De este modo, la discusión de este asunto se proyectó sobre la nueva Comisión Mixta de carácter técnico, o segunda Comisión técnica, que comenzó a reunirse a partir de octubre de $1858^{25}$. Si bien el gobierno español daba oficialmente por válidas las decisiones adoptadas por la primera Comisión técnica y se negó a reconocer de nuevo, de forma conjunta, los tramos previamente recorridos por esta, incluido el del Miño, lo cierto es que, por su cuenta y de forma separada, las delegaciones de ambos países efectuaron nuevos reconocimientos e informes en relación con las cuestiones territoriales previamente suscitadas.

Por la parte española, en julio de 1858, con anterioridad, pues, a la constitución formal de la segunda Comisión técnica, el gobierno envió al nuevo presidente de su delegación, el diplomático Salvador Tavira, un documento de instrucciones en las que, aunque se insiste en la postura favorable del gobierno a los acuerdos alcanzados por la primera Comisión, se le solicita que verifique de nuevo el deslinde ya efectuado en dicho tramo de frontera antes de que se constituya la nueva Comisión, al objeto de adquirir un conocimiento adecuado del terreno y una comprensión tanto de las ventajas obtenidas de la adjudicaciones hechas por la primera Comisión, como de la importancia de las cuestiones aún pendientes. En el mismo documento, el gobierno recuerda la relevancia del asunto de las pesquerías del Miño y, aunque consigna que el tema habrá de solucionarse cuando la Comisión aborde la elaboración de un reglamento internacional «con el objeto de dar iguales derechos y garantías a los súbditos de ambas

25. La composición de esta segunda Comisión técnica varió a lo largo de su período de actividad. En la sección española, formaron parte de ella inicialmente los diplomáticos Salvador Tavira (presidente), Evaristo Pérez de Castro (secretario) y Fidencio Bourman y Carvajal, hijo de Fidencio Bourman Monsegur, que había sido presidente de la sección española de la primera Comisión técnica. En diciembre de 1858 Tavira cesó y la presidencia de la sección española recayó de nuevo en Fidencio Bourman Monsegur, y desde julio de 1861 también se incorporó a dicha sección el comandante de Estado Mayor José de Castro López. En la sección portuguesa, formaron parte de la Comisión inicialmente el ingeniero militar José de Vasconcelos e Sá (presidente) y el mayor José Maria Delorme Colaço (secretario), ambos parlamentarios. El primero fue sustituido interinamente por Jacinto da Silva Mengo (oficial-consejero del Ministerio dos Negócios Estranjeiros) en la etapa final de esta Comisión técnica, mientras que el segundo fue reemplazado sucesivamente por los militares Carlos F. Pinheiro de Lacerda y Antonio A. Macedo e Couto. 
naciones para la libre pesca y navegación del río» ${ }^{26}$, encarga a Tavira que realice un estudio detallado de las pesquerías portuguesas y que inste a las autoridades fronterizas españolas a que estén pendientes de posibles nuevas construcciones que impidan la navegación o perjudiquen a los intereses españoles.

Como resultado de dicho estudio practicado por Tavira en las dos orillas del Miño a lo largo de los meses de agosto y septiembre de 1858, el comisario español mandó levantar un plano «de la parte del río Miño, desde Caldelas hasta la ciudad de Tuy, por ser este trayecto, por sus especiales circunstancias, el más digno de fijar la atención», en el que quedaron consignados los sitios exactos en que se habían construido los malecones, empalizadas y pesquerías (marcándose también aquellas que se encontraban camufladas o sepultadas por la tierra o las aguas), así como sus dimensiones, propietarios y otros datos relevantes. El informe de Tavira se plantea en buena medida como una descripción explicativa y minuciosa de la información representada en dicho plano, y se acompaña además de varios documentos y datos oficiales y privados relativos a las cuestiones abordadas en el mismo y recabados, bien durante su reconocimiento del terreno, bien a través del ayuntamiento y del cabildo de la catedral de Tui ${ }^{27}$.

Tavira insiste al gobierno español en que, a pesar de las alteraciones que esto supone para el curso natural del río, muchas de las obras defensivas que los españoles han realizado en la ribera derecha son indispensables para proteger sus terrenos de la inclinación que la corriente presenta por efecto de las pesquerías portuguesas y que provoca el frecuente anegamiento de esas zonas de cultivo. La «prosperidad y ventura» de estas zonas ribereñas, subraya Tavira, aconseja que el propio gobierno no sólo autorice dichas obras defensivas que permiten «enderezar» el cauce, sino que además «arbitre los medios» para la defensa de dichos espacios de cultivo y entable las negociaciones necesarias con el gobierno portugués para realizar los trabajos conducentes a recuperar el «estado navegable» del río, lo cual es esencial para el comercio.

26. «Instrucciones comunicadas al nuevo comisionado Sr Tavira al disponer pase a la frontera para empezar sus trabajos desde el límite de la provincia de Orense», documento fechado en Madrid a 2 de julio de 1855 (AHN, Sección M. ${ }^{\circ}$ de Exteriores, Tratados, Tr. 138, Neg. 207, Exp. 19).

27. El informe de Tavira, titulado «Observaciones descriptivas e históricas para la completa inteligencia del plano topográfico del río Miño, desde Caldelas al sitio de la barca del Pasage, de la ciudad de Tuy a Valença, según se hallaba en el verano de 1858», puede consultarse en AHN (Sección M. ${ }^{\circ}$ de Exteriores, Tratados, Tr. 136, Neg. 207, Exp. 15), y forma parte del despacho n. ${ }^{\circ} 11$ que Tavira remite al gobierno el 1 de enero de 1859, que incluye varios anexos de documentación con datos acerca de las pesquerías e informes de las autoridades locales, así como un detallado plano topográfico que Tavira manda levantar en 1858 («Plano topográfico del río Miño, desde los Baños de Caldelas hasta la barca de pasaje de la ciudad de Tuy a Valenza, en Portugal, según se hallaba en el presente...» en AHN, Sección M. ${ }^{\circ}$ de Exteriores, Mapas y Planos, 1139). El diseño final de este plano, fechado en Tui el 30 de noviembre de 1858, corrió a cargo del ingeniero civil Manuel de Uceda. 
Por la parte portuguesa, los trabajos para intentar que se revisaran las decisiones provisionales adoptadas por la primera Comisión técnica se iniciaron en febrero de 1859, cuando los comisionados José Vasconcelos e Sá y José María Delorme Colaço, presidente y secretario respectivamente de la delegación lusa, visitaron de nuevo el tramo fronterizo del Miño. En junio de ese mismo año ambos enviaron al gobierno portugués un relatório de este reconocimiento, acompañado de un plano propio y de una copia del levantado en 1855 por Madina y Orbeta ${ }^{28}$. En este informe se presenta de nuevo un análisis geomorfológico del origen y características del río Miño, a efectos de demostrar el origen aluvial de la mayoría de las islas que hay en él, así como la variabilidad natural de la altura, velocidad y anchura de sus aguas. Según los comisionados portugueses, dicho carácter cambiante del cauce no se ve sino reforzado por las alteraciones artificiales que en él han tenido lugar, siendo además muchas de las construcciones que allí hay contrarias a lo recogido en el derecho público internacional. En línea con el informe de Couvreur, se afirma que las islas de Verdoejo eran una sola en origen, acudiendo para ello tanto a argumentos geomorfológicos (según los comisionados portugueses, dicha isla original habría surgido a partir de la erosión ejercida por las aguas sobre una gran roca granítica, conocida como Pedra do Coelho, que a su vez dividió el río en dos brazos y formó, aguas abajo, tal isla); como a la documentación aportada por un tombo de 1691 y la Corografia portugueza de António Carvalho, en su edición de 1712, que describían esa isla entre los bienes del monasterio (en aquel entonces jesuita) de Sanfins. Posteriormente, según Vasconcelos y Colaço, la propiedad de la isla había pasado a los Condes de San Martinho (de nacionalidad portuguesa), a los que seguía perteneciendo en ese momento. A su vez, el desgajamiento de la isla, que Vasconcelos y Colaço atribuían al efecto de obras construidas en la orilla española (desplazando el thalweg original del río hacia la ribera portuguesa), había dado lugar a las de Canguedo y Raña Gallega ${ }^{29}$.

28. El mencionado plano ( «Planta das Ilhas de Verdoejo, no rio Minho, levantada en Fev. ${ }^{\circ}$ de 1859», a escala 1:20.000) está reproducido en Barreiros (1961-65: vol. I, fasc. I-II). El original puede consultarse en AHDMNE (Caja 1119, Fol. 232 y 317). Los informes de Vasconcelos y Colaço de 1859 está reproducidos en Barreiros (1961-65: vol. III, fasc. I-II, docs. 94, 95, 96 y 97).

29. A la luz de la documentación estudiada por Herzog (2015, 192 y ss.), que ha analizado el conflicto abierto en relación con esta isla a fines del XVII y principios del XVIII, entre el monasterio de Sanfins y el abad de la parroquia de Caldelas (apoyado por el obispado de Tui), algunos de los argumentos aportados por Vasconcelos y Colaço resultan en todo caso cuestionables: la propiedad de la isla de Verdoejo, que ya entonces estaba más próxima del lado español que del portugués, no quedó clara en el proceso judicial y político que se llevó a cabo en esos años para tratar de resolver esa contienda. En el proceso solo se pudo probar que tanto el monasterio de Sanfins como el abad de Caldelas y el Marqués de Bendaña (español) percibían y reclamaban tributos a los pescadores que utilizaban la isla, cuya disputa se desencadenó probablemente a partir de la confusión generada durante el dilatado período comprendido por 
En la opinión de los autores portugueses, el deslinde propuesto por la primera Comisión en este tramo fronterizo no se había hecho de acuerdo al reglamento general aprobado, puesto que ni se prestó la «atención debida» a los documentos históricos presentados (o, en su caso, se rebatieron con argumentos infundados), ni se llamó a testigos, autoridades o personas «imparciales» que pudieran dar cuenta de la antigüedad de la pertenencia portuguesa de las islas disputadas. Sin mencionar los argumentos expuestos en la memoria adjunta al plano de Madina y Orbeta (memoria que probablemente desconocían, pese a contar con la copia del plano), Vasconcelos y Colaço reprochaban, además, a los miembros que formaron parte de esa Comisión, un conocimiento insuficiente del terreno (sobre todo de cuál era el «curso natural»o antiguo del río, pues éste, y no el cauce nuevo creado por el efecto de las alteraciones artificiales, es el que debería servir para fijar el límite entre ambos reinos) y de la documentación preexistente. Asimismo, les recriminaban haberse excedido en sus propias competencias y atribuciones, pues en aquellas cuestiones conflictivas habrían debido requerir la opinión y autorización del gobierno portugués antes de proceder a los acuerdos.

Tiempo después, en abril de 1861, Vasconcelos e Sá envió otro extenso informe a su gobierno ${ }^{30}$ en que, repasando toda la trayectoria previa de las Comisiones Mixtas desde 1855 en adelante y abordando con detalle los asuntos fronterizos en litigio, volvía a alinearse con la postura general de Couvreur y suscribía también los argumentos desarrollados en el relatório redactado por el consejero del Ministerio dos Negócios Estranjeiros Jacinto da Silva Mengo en diciembre de $1860^{31}$. Vaconcelos cuestionaba una vez más los acuerdos alcanzados por la anterior Comisión y trataba de mostrar que, a su juicio, la sección española de ésta, o bien había invocado torticeramente algunos de los artículos de las instrucciones generales aprobadas para regular el funcionamiento y método de trabajo de la Comisión, o bien había actuado ignorándolos o conculcándolos. ${ }^{32}$ En consecuencia, Vasconcelos insistía en que en la isla Canosa debía continuar el uso común entre ambas partes (rechazando cualquier cesión

la unión política de ambas monarquías (1580-1640) y la posterior Guerra de Restauración (1640-1668), que devolvió la independencia a Portugal. Si en tiempos de dicha unión, durante la cual la funcionalidad tradicional de la frontera quedó suspendida, los habitantes de uno y otro lado del Miño habían compartido con normalidad el aprovechamiento de esta y otras islas, tras la separación definitiva de los reinos una de las partes (en este caso la portuguesa) reclamó la exclusividad de su uso o de su jurisdicción, provocando la oposición de la otra.

30. Reproducido en Barreiros (1961-65: vol. II, fasc. III-IV, doc. 42). Posteriormente, en noviembre de 1861 Vasconcelos remitía un nuevo informe, en este caso sobre la isla Canosa (reproducido en Barreiros, 1961-65:vol. I, fasc. I-II, doc. 14; y vol. II, fasc. III-IV, doc. 42).

31. Barreiros (1961-65: vol. II, fasc. I-II: 125-127)

32. En concreto, Vasconcelos considera que no se respetó el párrafo tercero de dichas instrucciones (que obligaba a los comisionados consultar con testigos y autoridades locales), el séptimo (que disponía que en los casos conflictivos se pospusieran los acuerdos y se sometiera a la consulta de los gobiernos), ni el primero (acerca de la rectificación de la frontera en cursos 
absoluta de la misma a España); y, en el caso de las de Verdoejo, recomendaba al gobierno portugués admitir todo lo más la cesión de la Ínsula Grande a España, pero con contrapartidas.

\section{El Tratado De LisboA, SU ANEXo SOBRE RÍOS LimítrofeS Y SU APLiCACIÓN}

A lo largo de 1863, los gobiernos de España y Portugal comenzaron a trabajar en la fase final de negociación del Tratado de Límites, que quedó encomendada a una Comisión Mixta de carácter diplomático reunida en Lisboa ${ }^{33}$. Esta Comisión, en contacto continuo con sus respectivos gobiernos, se reunió por primera vez el 30 de diciembre de 1863, concluyendo su primera misión el 29 de septiembre de 1864, en que se firma el Tratado, ratificado por las Cortes de ambos reinos y sancionado por Isabel II de España por decreto de 13 julio de 1865; y por Luis I de Portugal por decreto de 27 de marzo de 1866. Durante los dos años siguientes a la firma del Tratado, la Comisión diplomática, cuya composición se renovó parcialmente ${ }^{34}$, continuaría reuniéndose en Lisboa para negociar y redactar otros tres documentos claves en relación con el mismo: los dos Anexos al Tratado (que fijan los reglamentos, respectivamente, de ríos limítrofes y prendamientos de ganado), aprobados el 4 de noviembre de 1866; y las Instrucciones para ejecutar la demarcación de la frontera, aprobadas el 9 de ese mismo mes.

En lo que respecta a la delimitación del Miño, el Tratado de 1864 y su primer Anexo, relativo a los ríos limítrofes entre ambos países, contiene diversas disposiciones relevantes. En primer lugar, el Tratado de Límites de 1864, y sobre todo el citado Anexo, estipularon el criterio general que debía seguirse en la delimitación de la frontera fluvial tanto del Miño como de los restantes ríos fronterizos, fijando dicho límite en la mediana, con excepción de ciertas islas e

fluviales, pues se había ignorado la tendencia del Miño a variar y que la cuestión, por su relevancia, debía tratarse por la vía diplomática).

33. Por parte española, los plenipotenciarios designados a tal efecto fueron Juan Jiménez de Sandoval, Marqués de la Ribera (a la sazón embajador en Portugal desde enero de 1862), en calidad de presidente de la delegación, y Facundo Goñi, como secretario, asistidos por el comandante del Estado Mayor del Ejército José de Castro López, que ya colaboraba en la Comisión desde 1861. Por la portuguesa, actuaron como plenipotenciarios el Marqués de Loulé (Ministro de Negócios Estranjeiros), en calidad de presidente, y el consejero ministerial Jacinto da Silva Mengo, como secretario. Los principales documentos de las negociaciones se conservan en AHN, Sección M. ${ }^{\circ}$ de Exteriores, Tratados, TR. 135, Neg. 207, exp. 12 y TR 136, Neg. 207, exp. 13.

34. Así, en la delegación española, desde octubre de 1864 el Marqués de la Ribera cesó en la Comisión, asumiendo la presidencia Facundo Goñi, y pasando la secretaría de la misma a Evaristo Pérez de Castro. Por la parte portuguesa, el Marqués de Loulé cesó en 1865, sustituyéndole como presidente José da Silva Mendes Leal, mientras que Jacinto da Silva permaneció como secretario. 
islotes objeto de soluciones específicas ${ }^{35}$. En segundo lugar, y en relación con este último aspecto, el Tratado reparte la soberanía de las principales islas del Miño objeto de contencioso de la siguiente manera (artículo 1): de un lado, la isla Canosa, al igual que la Cancela, la Ínsula Grande y el islote de Filla Boa, fueron adjudicados a España; de otro, las islas de Canguedo y Raña Gallega fueron adjudicadas a Portugal. El Tratado confirma de este modo los acuerdos provisionales planteados por la primera Comisión técnica en junio de 1856, coincidentes a su vez con los argumentos elaborados por la delegación española en septiembre y octubre de 1855 en el sentido de asignar la soberanía de estas islas en función de su proximidad geográfica respectiva a una u otra orilla ${ }^{36}$. En el caso de la Canosa, el artículo 26 del Tratado acordó mantener el «derecho de extraer yerbas mancomunadamente» que hasta entonces venían disfrutando «los pueblos de ambos países». Y ese mismo artículo estipuló la necesidad de formar un «reglamento especial» que «establezca y fije para lo futuro las reglas convenientes respecto a la construcción de obras de cualquiera clase en las orillas de los ríos fronterizos, y particularmente en las del Miño y de sus islas».

Respondiendo a tal previsión, el Anexo sobre ríos limítrofes que acompañó el Tratado de 1864, sin perjuicio de ratificar el uso común de estas corrientes para los pueblos de los dos países (supeditados en cualquier caso a los pactos y reglamentos aprobados por sus respectivos gobiernos), estableció una serie de disposiciones al objeto de regular este uso y combatir los problemas que causaba la proliferación incontrolada de pesquerías, malecones defensivos y otras construcciones en las orillas de estos ríos, en especial en el Miño, «tanto porque

35. De manera un tanto imprecisa y ambigua, el Tratado de 1864 establece que «la línea de separación entre la soberanía del reino de España y la del reino de Portugal a partir de la desembocadura del río se dirigirá por el centro de la corriente principal del Miño hasta la confluencia del río Barjas o Troncoso». Pero esta expresión fue precisada a posteriori del Tratado en el sentido de la línea media del río (o línea central equidistante de ambas orillas), y no en el de thalweg. Así aparece en el artículo 1 del Anexo o Reglamento sobre ríos limítrofes, en que se dice todos los cursos fluviales fronterizos comprendidos en el Tratado de 1864 pertenecen «por la mitad de sus corrientes a ambas naciones», así como en el Acta general de demarcación, aprobada en Lisboa el 1 de diciembre de 1906, que, en su Segunda Parte, artículo 3, ratificará y completará este principio. Los tres textos legales mencionados pueden verse en MAEC (2005: 151 y ss.)

36. Las instrucciones dadas a F. Bourman el 30 de noviembre de 1862 por el Ministerio de Estado para negociar el Tratado de Límites, asumidas posteriormente por el Marqués de la Ribera y Goñi, establecían en este sentido: «Con respecto a la división alcanzada hasta ahora en la provincia de Pontevedra, se considera que se ha hecho bien siguiendo el criterio en el Miño de ceder las islas a aquel país al que estuvieran más próxima (solución considerada equitativa), de manera que España se ha quedado con la Isla Canosa, la Cancela y la Insula Grande, y el islote Filla Boa que es propiedad de los condes de Salvatierra, y accede a los deseaos de los comisionados portugueses de que se continúe con la comunidad de pastos y yerbas para los súbditos de las dos naciones en la Canosa» (AHN, Sección M. ${ }^{\circ}$ de Exteriores, Tratados, TR. 135, Neg. 207, exp. 12). 
se embaraza la navegación y se dificulta el uso y aprovechamiento públicos, como porque se altera el curso de las aguas con daño a un mismo tiempo de las propiedades particulares situadas en las márgenes fluviales, y de la soberanía territorial de uno y otro Estado» ${ }^{37}$. En este sentido, el artículo 4 de dicho Anexo acordó prohibir:

construir en los ríos ni en sus orillas, o en las de sus islas, obras de ningún género que perjudiquen a la navegación, o alteren el curso de las aguas, o dañen en cualquiera manera a las condiciones de los ríos para el uso común y público. Por tanto queda por punto general prohibida la construcción de todo género de obras, como son molinos o aceñas, presas fijas o movibles, malecones, pesquerías, canales, empalizadas y otras cualquiera que puedan causar embarazo o daño al interés público (MAEC, 2005: 167).

El reglamento permite, no obstante, construir obras que no causen los perjuicios descritos y estipula el procedimiento para su tramitación, atribuyendo a los gobernadores civiles de provincia (en España) y de distrito (en Portugal) la competencia para autorizar o denegar las solicitudes, previo dictamen pericial (art. 5). Asimismo, se establece la obligación de verificar anualmente un reconocimiento de los ríos fronterizos, tarea que se encomienda a los alcaldes españoles y administradores de concejo portugueses, acompañados de delegados municipales (art. 8); y se fijan las sanciones y penas que deben imponerse a los infractores del reglamento (art. 9). Finalmente, el artículo transitorio de ese mismo Reglamento, «teniendo presente la situación excepcional del río Miño», prevé efectuar un reconocimiento de la frontera definida por este río por dos ingenieros (uno de cada país) al objeto de verificar y describir, entre otros aspectos, todos aquellos «obstáculos que embaracen la navegación en los diversos parajes, los medios de removerlos y las obras que juzguen necesario construir o demoler, tanto para hacer el río navegable como para regularizar el curso de sus aguas $»^{38}$. En la práctica, el cumplimiento efectivo de estas tareas técnicas se demoró considerablemente y acabó siendo confiando a la Comisión de Límites que preparó el Acta de entrega de la línea fronteriza del Miño, firmada en Lisboa el 30 de mayo de 1897, siendo presidentes de dicha Comisión Ignacio Salinas Angulo (general del Estado Mayor del Ejército español) y Sebastião Lopes de Calheiros e Meneses (general del Estado Mayor del Ejército portugués) ${ }^{39}$.

37. Reglamento relativo a los rios limitrofes entre ambas Naciones (en MAEC, 2005: 163-171). La cita textual corresponde al preámbulo, pp. 165-166.

38. Ibid.

39. Acta relativa a la entrega del río Miño que sirve de frontera entre España y Portugal desde su desembocadura hasta la confluencia del río Barjas o Troncoso. Un original completo de este documento se halla en AHN, Sección M. ${ }^{\circ}$ de Exteriores, Tratados, TR 152, Neg. 224, exp. 8. El articulado y la descripción del río Miño que lo acompaña han sido reproducidos en García Mañá (1993: 251-289) 
Esta Acta incluye un articulado que describe con detalle el trazado de la línea fronteriza definida por el Miño y dispone diversas medidas para ejecutar el reglamento de 1866; una descripción geográfica general, minuciosa y sistemática, del río y de sus orillas; y un repertorio exhaustivo y detallado de todas las obras artificiales existentes a lo largo de este tramo de la raya, de las que se contabilizan un total de 778 (incluyendo pesqueras de piedra, estacadas de madera, muelles, dársenas, muros de contención, rampas para embarcaciones, etc.). Además, el Acta se acompaña de un Atlas o Plano de la línea fronteriza definida por el río Miño a escala 1:2.500, en 59 hojas, levantado por los comisionados y capitanes de Estado Mayor Gaspar Antonio de Azevedo (portugués) y Miguel Correa Oliver (español), en el que se localizan y representan no sólo obras inventariadas en el Acta, sino también otras muchas informaciones geográficas (Comisión Internacional de Límites entre España y Portugal, 1898). Tanto el Atlas como la referida descripción geográfica general incluida en el Acta constituyen una fuente extraordinariamente rica y útil para reconstruir el paisaje y la organización espacial de este sector de la frontera a fines del xIX, y cuya elaboración y contenido hemos analizado en otro lugar (García y Puente, 2015b). Por lo que toca al articulado del Acta, conviene destacar las consideraciones incluidas en los artículos 5 y 6: el primero concluye, a partir del reconocimiento previo del tramo fronterizo del Miño, «que las obras ejecutadas en la parte del río cuyas orillas son bajas o bien que son escarpas de tierra ejercen una acción paulatina [en el curso natural de las aguas] cuyo resultado sólo puede apreciarse en el trascurso de mucho tiempo»; mientras que el segundo enumera las pesqueras que «es preciso modificar o destruir a causa de su perniciosa influencia en el régimen de las aguas», y que suman un total de once (siete en el margen derecho, cuatro en el izquierdo).

\section{RECAPITULACIÓN Y CONCLUSIONES}

A pesar de tratarse de una frontera de carácter marcadamente natural y de considerable antigüedad histórica, cuyos orígenes se confunden con los del propio reino de Portugal, la delimitación moderna y definitiva de la raya hispanoportuguesa definida por el río Miño constituyó uno de los capítulos más controvertidos del proceso de elaboración y negociación del Tratado de Límites de 1864. Desde el momento en que, en septiembre de 1855, las Comisiones Mixtas encargadas de preparar el Tratado abordaron el reconocimiento de este tramo, el primero de la raya en ser examinado, quedaron de manifiesto las principales dificultades que entrañaría su demarcación, y que, como se ha expuesto en este trabajo, pueden sintetizarse en tres, en cualquier caso estrechamente relacionadas entre sí: la existencia de varias islas fluviales de soberanía confusa o disputada; la proliferación de pesquerías, estructuras defensivas y otras obras que 
alteraban artificialmente el curso de la corriente, con consecuencias negativas diversas; y la acusada variabilidad del cauce y curso del río. Los tres asuntos dieron pie a numerosas y prolijas discusiones en el seno de las Comisiones y de los gobiernos y cancillerías respectivos, las cuales movilizaron y a la vez generaron un importante corpus de documentación en el que se incluyen varias memorias, informes, croquis, planos y mapas de considerable interés geográfico y cartográfico, elaborados en su mayor parte por los militares (ingenieros y, posteriormente, oficiales del Estado Mayor del Ejército) que participaron en dichas Comisiones.

Para dirimir la soberanía sobre las islas fluviales disputadas, los argumentos planteados por cada una de las partes en defensa de sus intereses apelaron simultáneamente a principios del derecho internacional, al conocimiento directo y científico del terreno (incluyendo su representación cartográfica), a los documentos históricos (especialmente jurídicos) que pudieran acreditar una posesión continuada de los terrenos en litigio y a los testimonios de los vecinos y autoridades locales. Pero pese a la extensa y variada documentación manejada por ambos países, y pese a la no menos amplia tipología de razones que se adujeron sobre la base de la misma, el criterio que finalmente prevaleció en el Tratado fue el de asignar dichas islas en función de su proximidad geográfica a una u otra orilla, defendido desde el inicio por la parte española, que lo consideraba no sólo el más «equitativo», sino también, según quedó constancia en los informes de F. Bourman y R. Madina, el más aconsejable desde el punto de vista de la defensa del territorio nacional y del control policial del contrabando. Solventada esta cuestión de acuerdo con las pretensiones españolas, la constatación de la variabilidad del cauce del Miño, atribuida principalmente al efecto de las numerosas pesquerías construidas a uno y otro lado del mismo, motivó las otras dos decisiones claves adoptadas en el Tratado de 1864 y en su primer Anexo en relación no sólo con el Miño, sino con el resto de los ríos limítrofes afectados por dicho Tratado: trazar -con las excepciones insulares señaladas- la línea fronteriza por la mediana de tales ríos (en vez de por su thalweg), de conformidad con el criterio seguido habitualmente en estos casos en el derecho internacional; y prohibir en adelante la construcción, en los ríos o en sus orillas e islas, de todas aquellas obras artificiales que causaran perjuicio al «interés público».

En relación con este último aspecto, la documentación analizada en el presente trabajo permite resaltar que el proceso de delimitación fronteriza entre España y Portugal en el río Miño, lo mismo que en otros sectores fluviales relevantes dentro de la raya, resulta indisoluble de otros objetivos más amplios y ambiciosos, dirigidos a la gestión y la ordenación racional de estos espacios, así como a su fomento o desarrollo. El establecimiento por el Tratado y su primer Anexo de diversas medidas para regular, controlar y prohibir en el futuro la construcción de dichas obras, así como para destruir aquellas ya existentes que 
se demostraran contrarias al interés público, se consideraba esencial a efectos de impulsar un abanico amplio de beneficios políticos, sociales y económicos, la mayoría de los cuales aparecen también recogidos en los informes elaborados por los miembros de las Comisiones Mixtas de Límites en relación con el Miño: atenuar la frecuencia, intensidad e impacto de las crecidas fluviales sobre los pueblos ribereños; mejorar la navegabilidad del río y la actividad comercial en torno al mismo, e incluso extenderlas aguas arriba hasta localidades que en el pasado habían sido accesibles al tráfico fluvial mercantil, como Ribadavia; combatir la formación de islas, arenales y otro tipo de accidentes fluviales aprovechados frecuentemente para la práctica del contrabando; o, en fin, como reza el preámbulo del Tratado de 1864, «establecer y consolidar la paz y la armonía entre las poblaciones limítrofes», poniendo coto a uno de sus principales motivos de disputa.

Más allá de definir la línea fronteriza en términos precisos y de solucionar las cuestiones o contenciosos territoriales principales entre ambos países, tanto el Tratado de Límites de Lisboa y sus Anexos como las Comisiones que lo prepararon hubieron, pues, de dar respuesta a un conjunto de problemas recurrentes en las fronteras ibéricas, o en ciertos sectores de ellas, relacionados en su mayor parte con determinados usos y aprovechamientos tradicionales de estos espacios, como los abordados en el primer Anexo del Tratado o los que motivaron el segundo Anexo del mismo, por el que se regulan los prendamientos del ganado que atravesara la frontera para pastar en el país vecino. Y es en este sentido que, situado en un horizonte teórico y comparativo más amplio, ibérico e internacional (García y Puyo, 2015b), el estudio de los procesos de delimitación fronteriza ofrece un enorme interés no sólo para la historia del conocimiento geográfico y para la geografía histórica de estas regiones, sino también, o de manera más amplia, para la historia del territorio y de las ideas y prácticas territoriales que conformaron los Estados modernos.

\section{FUENTES Y BIBLIOGRAFÍA}

AGA: Archivo General de la Administración (Alcalá de Henares, Madrid).

AHN: Archivo Histórico Nacional (Madrid).

AHDMNE: Arquivo Histórico e Diplomático do Ministério dos Negócios Estrangeiros (Lisboa).

Alfonso X (1767): Las Siete Partidas, edición de Joseph Berní y Catalá, Valencia, Imprenta de Benito Monfort.

Alonso Rodríguez, E. (1989): Pescadores del río Miño (tramo gallego-portugués). Diputación de Pontevedra. Pontevedra.

Barreiros, J. B. (1961-1965): «Delimitaçao da fronteira luso-espanhola», en O Distrito de Braga, vol I, fasc. I-II y III-IV (1961), vol. 2, fasc. I-II (1963) y II-IV (1964), y vol 3, fasc. I-II y III-IV (1965). 
Barros, C. (1994): «La frontera medieval entre Galicia y Portugal», en Medievalismo, n. ${ }^{\circ} 4$, pp. $27-39$.

Bouchez, L. J. (1963): «"The Fixing of Boundaries in International Boundary Rivers», en International and Comparative Law Quarterly, n. ${ }^{\circ}$ 12, pp 789-817.

CAFlisch, L. (1989) : «Regles generales du droit des curs d'eau internationaux», en Recueil des Curs de l'Academie de Droit International de la Haye, n. ${ }^{\circ} 219$, vol. VII, pp. 9-224.

Cairo, H.; Godinho, P. (2013) «El Tratado de Lisboa de 1864: la demarcación de la frontera y las identificaciones nacionales», Historia y Política, n. ${ }^{\circ}$ 30, pp. 23-54.

Cajal, M. (2003): Ceuta, Melilla, Olivenza y Gibraltar. ¿Dónde acaba España?, Madrid, Siglo XXI.

CApDevila, J. (2009): Historia del deslinde de la frontera hispano-francesa. Del tratado de los Pirineos (1659) a los tratados de Bayona (1856-1868). IGN-CNIG. Madrid.

Comisión Internacional de Límites entre España y Portugal (1898): Plano del río Miño desde su desembocadura hasta la confluencia del río Barjas o Troncoso, levantado en escala de 1:2.500 por los oficiales de la Comisión Comandante de E.M. D. Miguel Correa Oliver y el Mayor de E.M. D. Gaspar Antonio d'Acevedo Meira.

De la Rasilla Del Moral, I. (2013): «El estudio del Derecho internacional en el corto siglo XIX español», en Rechtsgeschichte - Legal History, 21, pp. 48-65.

De Olmeda y León, J. (1771): Elementos del derecho público de la paz y la guerra: ilustrados con noticias históricas, leyes y doctrinas del Derecho Español. Imprenta de la viuda de Manuel Fernández. Madrid, 2 tomos.

De Pando, J. M. (1843): Elementos del derecho internacional. Imprenta de Alegría y Charlain. Madrid.

Del Vas Mingo, M. (1999): «La problemática de la ordenación territorial en Indias (SS. XVI-XVIII)», en Revista complutense de historia de América, n. ${ }^{\circ}$ 25, pp. 67-98.

Dias, M. H. (2009): Finis Portugalliae - Nos confins de Portugal. Cartografía militar e identidad territorial. Instituto Xeográfico do Exército. Lisboa.

Freire, D., Rovisco, E., Fonseca, I. (corrds.) (2009): Contrabando na fronteira LusoEspanhola. Práticas, Memórias e Patrimónios. Edições Nelson de Matos. Lisboa.

García, J., Puente, P. (2015a): «Las Comisiones Mixtas de Límites y las representaciones geográficas de la frontera hispano-portuguesa (1855-1906)», en Revista de Historiografía, n. ${ }^{\circ}$ 23, pp. 67-100.

- (2015b): «La delimitación de la frontera luso-española en el río Miño (1855-1906): conflictos territoriales y representaciones cartográficas», en Terra Brasilis, (Nova Serie), (on line), n. ${ }^{o}$ 6, url.: http://terrabrasilis.revues.org/1708.

García, J., PuYo, J.-Y. (2015): «La aportación geográfica y cartográfica de las Comisiones de Límites luso-franco-españolas (siglos XVIII-XIX). Apuntes para una historia comparada del conocimiento y la cooperación científica sobre la frontera», en Terra Brasilis, (Nova Serie), (on line), n. ${ }^{\circ}$ 6, url.: http://terrabrasilis.revues. org/1693.

García Mañá, L. M. (1993). Miño: ¿existiu unha fronteira?. Galaxia. Vigo.

- (2000): Couto Mixto. Unha república esquecida. Universidade de Vigo. Vigo. 
GÉRARD de Rayneval, J. M. (1821): Instituciones del Derecho natural y de gentes. Traducción de M. Antonio López. Imprenta de la Compañía. Madrid.

Godinho, P. (2011). Oír o galo cantar dúas veces. Deputación Provincial de Ourense. Ourense.

Gómez DE LA Torre, J. M. (2005): «Régimen legal de los cursos de aguas internacionales», en AFESE, n. ${ }^{\circ}$ 42, pp. 101-124.

Grocio, H. (1925): Del Derecho de la guerra y de la paz. Traducción de J. Torrubiano Ripoll, Madrid. Ed. Reus.

Herzog, T. (2015): Frontiers of posession. Spain and Portugal in Europe and the Americas. Harvard University Press. Cambridge.

KaECKenbeecK, G. (1918): International Rivers. Sweet and Maxwell. Londres.

Maec (2005): Acuerdos fronterizos con Portugal y Francia. Colección de recopilaciones, Vol. 1.: 1297-2004. Portugal. Secretaría General Técnica. Ministerio de Asuntos Exteriores y de Cooperación. Madrid.

Morales, A. de (1998): «La difusión del derecho natural y de gentes europeo en la universidad española de los siglos XVIII y XIX», en Doctores y escolares. El congreso internacional de Historia de las universidades Hispánicas (Valencia 1995). Universidad de Valencia. Valencia, pp. 49-60.

Prescott, V. y Triggs, G. (2008): International Frontiers and Boundaries. Martinus Nijhof. Leiden - Boston.

Río, F. J. y Rodríguez, F. (1992): Os ríos galegos. Morfoloxia e réxime. Consello da Cultura Galega. Santiago de Compostela.

Riquelme, A. (1849): Elementos de derecho público internacional, con esplicacion [sic] de todas las reglas, según los tratados, estipulaciones, leyes vigentes y costumbres, constituyen el derecho internacional español. Imprenta de Santiago Saunaque. Madrid, 2 vols.

Sereno, A. (2011): Ríos que nos separan, aguas que nos unen. Análisis jurídico de los convenios hispano-lusos sobre aguas internacionales. Fundación Lex Nova. Valladolid.

Teclaff, L. A. «The River Basin Concept and Global Climate Change», en Pace Environmental Law Review, n. ${ }^{\circ}$ 8, pp. 355-88.

Teixeira De SAmpaio, L. (2001): Compilaçao de elementos para o estudo da questao de Olivença. AAAHD-GAO. Lisboa.

Union AcademiQue Internationale (1960): Dictionnaire de la Terminologie du Droit International. Sirey. París.

Vattel, E. (1820): Derecho de Gentes o Principios de la Ley Natural aplicados a la conducta y a los negocios de las naciones y los soberanos. Traducción de M. Pascual Hernández. Madrid. Imprenta de la Compañía.

Zusman, P. (2000): Tierras para el Rey. Tres fronteras y la construcción nacional del territorio del Rio de la Plata. Tesis Doctoral. Universidad Autónoma de Barcelona. Barcelona. 